\title{
Factors influencing local food procurement among women of reproductive age in rural eastern and western North Carolina, USA
}

\author{
Jared T. McGuirt, ${ }^{\text {a* }}$ University of North Carolina at Chapel Hill \\ Rachel Ward, ${ }^{\mathrm{b}}$ East Tennessee State University \\ Nadya Majette Elliott, ${ }^{\mathrm{c}}$ East Carolina University \\ Sally Lawrence Bullock, ${ }^{\mathrm{d}}$ University of North Carolina at Chapel Hill \\ Stephanie B. Jilcott Pitts, ${ }^{\mathrm{e}}$ East Carolina University
}

\begin{abstract}
Submitted December 31, 2013 / Revised March 13, 2014 / Accepted April 12, 2014 /
Published online August 12, 2014

Citation: McGuirt, J. T., Ward, R., Majette Elliott, N., Lawrence Bullock, S., and Jilcott Pitts, S. B.

(2014). Factors influencing local food procurement among women of reproductive age in rural

eastern and western North Carolina, USA. Journal of Agriculture, Food Systems, and Community

Development, 4(4), 143-154. http://dx.doi.org/10.5304/jafscd.2014.044.004
\end{abstract}

Copyright (C) 2014 by New Leaf Associates, Inc.

a* Corresponding author: Jared T. McGuirt, MPH, Research Assistant, Department of Nutrition, University of North Carolina at Chapel Hill; 2200 McGavran-Greenberg Hall; Chapel Hill, North Carolina 27599 USA; +1-910-249-2296; mcguirtj@live.unc.edu

b Rachel Ward, MPH, Research Assistant, Department of Community Health, East Tennessee State University; Johnson City, Tennessee USA; +1-828-808-7913; wardrk@goldmail.etsu.edu

c Nadya Majette Elliott, MPH, Research Assistant, Department of Public Health, East Carolina University; 600 Moye Boulevard, MS 660; Greenville, North Carolina 27834 USA; +1-252-744-4034; majetten@ecu.edu

d Sally Lawrence Bullock, MPH, Research Assistant, Department of Nutrition, University of North Carolina at Chapel Hill; 2200 McGavran-Greenberg Hall; Chapel Hill, North Carolina 27599 USA

e Stephanie B. Jilcott Pitts, PhD, Associate Professor, Department of Public Health, East Carolina University; 600 Moye Boulevard, MS 660 Lakeside Annex 7; Greenville, North Carolina 27834 USA; +1-252-744-5572; jilcotts@,ecu.edu

\begin{abstract}
Little is known about the barriers and facilitators to local food procurement among women of reproductive age (WRA). Therefore we conducted qualitative interviews with WRA in rural eastern and western NC (ENC and WNC) to learn of factors related to locally sourced food procurement. In-depth interviews were conducted among low-income White, Black, and Hispanic Englishspeaking WRA ( $N=62$ (ENC: 37; WNC: 23) (1844 years)). Independent coders used a consensus codebook to double-code all transcripts. Coders then came together to discuss and resolve coding discrepancies, and identified themes and salient quotes. Cross-cutting themes from both ENC and WNC participants included access to local food sources; acceptance of Supplemental Nutrition Assistance Program/Electronic Benefit Transfer (SNAP/EBT); freshness of produce; support for local agriculture; and the community aspect of local food sourcing. The in-depth understanding gained
\end{abstract}


from this study could be used to guide tailored policy and intervention efforts aimed at promoting fruit and vegetable consumption among lowincome WRA.

\section{Keywords}

farmers' markets, food stamps, rural, women of reproductive age, local food, $\mathrm{SNAP} / \mathrm{EBT}$

\section{Introduction}

The prevalence of diet-related chronic diseases, including obesity, diabetes, heart disease, and cancer, disproportionately burdens rural populations in the United States. (Freeman, 1989; Winkleby, Jatulis, Frank, \& Fortmann, 1992). The cause of this high prevalence is likely multifactorial in nature, but may be due in large part to insufficient consumption of low-calorie, nutrient-dense foods like fruits and vegetables (Chiuve, Sampson, \& Willett, 2011). Rural residents tend to consume fewer fruits and vegetables than their urban counterparts (Lutfiyya, Chang, \& Lipsky, 2012), and low-income rural residents have particularly low levels of fruit and vegetable consumption (Lin, 2005). The comparatively lower levels of healthy food consumption among rural residents may be due to disparities in access to healthier foods. Multiple research studies (Fisher \& Strogatz, 1999; Larson, Story, \& Nelson, 2009; Liese, Weis, Pluto, Smith, \& Lawson, 2007; Powell, Slater, Mirtcheva, Bao, \& Chaloupka, 2007; Sharkey \& Horel, 2008) have suggested that rural residents are most often affected by poor access to food stores that offer healthful food products, such as supermarkets and chain grocery stores. One representative national study found that rural areas had 14 percent fewer chain supermarkets than urban areas (Powell et al., 2007), and another study found that U.S. counties defined as "low access" (counties in which at least one-half of the population lives more than 10 miles or $16 \mathrm{~km}$ from a supermarket or supercenter) were more concentrated in rural areas (Morton \& Blanchard, 2007).

Many strategies have been proposed to increase access to healthier foods in this population. Some have promoted using locally produced foods to improve food access through directmarketing approaches like farmers' markets and produce stands (Fisher, 1999; McCormack, Laska, Larson, \& Story, 2010). While there is little published literature documenting a potential relationship between shopping at local food sources and increased fruit and vegetable consumption, there is evidence that those who shop at farmers' markets report greater produce consumption than those who do not (Jilcott Pitts, Wu, McGuirt, Crawford, Keyserling, \& Ammerman, 2013), and evidence for the effectiveness of these sources in increasing consumption (Evans, Jennings, Smiley, Medina, Sharma, Rutledge, Stigler, \& Hoelscher, 2012). Thus using local food sources may be a promising approach to improve healthy food accessibility and consumption among low-income, rural residents.

While this may be a promising approach, local food sources are often underutilized by lowerincome individuals (Byker, Shanks, Misyak, \& Serrano, 2012). The reasons for this remain unclear. In a quantitative study surveying mostly female limited-resource North Carolinians, Leone, Beth, Ickes, MacGuire, Nelson, Smith, Tate, and Ammerman (2012) found that low-income individuals cited not being able to use food assistance program benefits and not knowing of farmers' market in their area as barriers to shopping at farmers' markets, with some racial and geographic differences. Racine, Smith Vaughn, and Laditka (2010) conducted surveys among Special Supplemental Nutrition Program for Women, Infants, and Children (WIC) participants and found that barriers to farmers' market shopping included lack of farmers' markets close to home and lack of transportation to farmers' markets. While these quantitative findings are informative, there is a need for a more in-depth, qualitative approach to more thoroughly understand the barriers and facilitators to purchasing healthy foods from direct marketing venues (e.g., farmers' markets, produce stands).

Women of reproductive age (WRA) are a particularly important population to study in regard to food access, as women are often the primary food shoppers for their homes (GfK Custom Research North America, 2013), and the dietary choices of WRA are important for fetal development (Daly, Kirke, Molloy, Weir, \& Scott, 1995; Ray, Wyatt, Vermeulen, Meier, \& Cole, 2005; 
Sinning, 1998; World Health Organization [WHO] \& Food and Agriculture Organization of the United Nations [FAO], 2004). Among rural WRA, an in-depth understanding of the facilitators and barriers to procuring food at direct-marketing venues such as farmers' markets and produce stands is not currently available. This information could be used to inform future intervention and policy efforts to increase fruit and vegetable purchasing and consumption by promoting use of direct-marketing venues among WRA. Additionally, an assumption is often made that rural women are homogenous in their views of local food sources and the barriers faced in procuring food from these sources. This assumption may be inaccurate, as rural areas are often heterogeneous in terms of geography, culture, and demographics, which might lead to differences in views of local food procurement. Additional information is needed to more clearly understand both the differences and similarities of distinct rural populations. Therefore, we conducted qualitative interviews with WRA in rural eastern and western NC (ENC and WNC) in order to learn of factors related to local food procurement.

\section{Methods}

\section{Study Setting and Participants}

Qualitative interviews were conducted with women $(\mathrm{N}=62)$ regarding their food-shopping patterns. Like many states in the mid-Atlantic region of the United States, there are rural populations in both mountainous areas and coastal plain regions of North Carolina (NC). Women were selected from two separate regions in $\mathrm{NC}$ that experience high burdens of chronic disease and are distinct in terms of geography, topography (eastern NC is a coastal plain regions, and western $\mathrm{NC}$ is a mountainous region in Appalachia), and culture, to examine whether there were differences and similarities in findings across different rural populations. Women were proactively recruited from two locations: the WNC sample $(\mathrm{n}=23)$ was recruited from a WIC clinic at a local health department, and the ENC sample $(n=37)$ was recruited from a Title X Family
Planning clinic $^{1}$ at a local health department. With the assistance of the WIC dietitian, a study staff member recruited participants in the WNC sample during their visits to the health department for WIC appointments. Participants in the ENC sample marked on a questionnaire that they were interested in the study, and then were called to be screened for potential participation. Participants were reimbursed for their time (ENC: US $\$ 40$; WNC: US\$25). The sample consisted of lowincome White, Black, and Hispanic Englishspeaking women of childbearing age (18-44 years). To be eligible, participants had to be the primary food shopper for their home and be White, Black, or Hispanic, English-speaking WRA (18-44 years). Study procedures and the interview guide received approval from the Institutional Review Board (IRB) at East Carolina University for the ENC sample (IRB \# 10-0634), and East Tennessee State University IRB (C0612.21s) for the WNC sample. All participants provided written informed consent.

\section{In-depth Interview Protocol}

Interviewers met participants in a community location that was convenient to the participant (e.g., library, health department). During the meeting participants were informed of all aspects of the study and were offered a chance to ask questions. The in-depth interviews lasted 25 to 60 minutes, and were audio-recorded with a digital recorder. Detailed notes were also taken by the interviewer. All participants gave verbal permission to record the interview. The interviews were de-identified, and then transcribed verbatim.

The interview guide was developed through a collaborative effort by the study team comprising researchers from ENC and WNC. Interview topics included neighborhood definitions, travel behaviors, and, of interest for this study, frequency of shopping, venues accessed most frequently, reasons for selecting those venues, direct-marketing venues and local food sources, and procurement strategies. The interview guide was then pilot tested among study staff (with staff administering and

\footnotetext{
${ }^{1}$ Title $\mathrm{X}$ is a federal grant program providing low-income individuals with family planning and related preventive health services.
} 
participating in practice runs of the full interview guide under realistic study conditions), and appropriate revisions were made.

\section{Data Analysis}

Five data-rich transcripts were reviewed by two independent coders to develop a consensus code book with potential codes and corresponding operational definitions. All transcripts were systematically double coded in ATLAS.ti software using descriptive codes, with each researcher independently coding the same interview using the consensus codebook. Coders met to revise the codebook, resolve disagreements on how to apply codes, add or delete codes, and come to consensus on how to code segments of text. The research team then identified emerging relevant themes and salient quotations to illustrate each theme. Relevant themes were identified as those that were mentioned by at least three women. To further examine possible racial differences in the factors influencing the procurement of food from the farmers' market, the research team stratified the ENC results by race and examined the differences qualitatively.

\section{Results}

\section{Participant Demographics}

Details of participant demographics for both the ENC and WNC samples can be found in Table 1.
Table 1. Participant Demographics (Divided by Eastern and Western North Carolina (ENC and WNC))

\begin{tabular}{lcc}
\hline Variable & ENC $=\mathbf{n}(\%)$ & WNC $=\mathbf{n}(\%)$ \\
\hline Age & $2(6 \%)$ & $1(4 \%)$ \\
$18-20$ & $22(59 \%)$ & $12(52 \%)$ \\
$20-29$ & $10(27 \%)$ & $9(39 \%)$ \\
$30-39$ & $3(8 \%)$ & $1(4 \%)$ \\
$40-44$ & $15(41 \%)$ & $23(100 \%)$ \\
\hline Race & $22(59 \%)$ & $0(0 \%)$ \\
White & $18(49 \%)$ & $10(43 \%)$ \\
Black & $19(51 \%)$ & $\mathrm{N} / \mathrm{A}$ \\
\hline Employed & $5(14 \%)$ & $23(100 \%)$ \\
\hline SNAP Participants &
\end{tabular}

In the ENC sample, the majority of participants reported Black race $(59 \%)$, and the rest reported White race (41\%). The mean age of participants was 27.6 years (range, 18-41 years). The participants were evenly split in employment status (employed, 49 percent; not employed, 51 percent), and Supplemental Nutrition Assistance Program (SNAP) use (yes, 51 percent). For the WNC sample, all the participants (100\%) were White, which is representative of the population demographics of the county from which they were recruited (97 percent White) (U.S. Census Bureau, 2013). The mean age of participants was 29.7 years

\section{Table 2. ENC Reasons for Procuring Food from Local Food Sources}

\begin{tabular}{ll}
\hline Theme & Quotation \\
\hline Freshness of produce & “I love going to farmers' markets. Sometimes I want to go really bad. Like the other day I \\
cooked some string beans, I like to cook fresh food, not out of the can. And I went to \\
[regional supermarket] and I got some, and they were molded. And I had to pick the mold \\
out of them. But if I would have went to the farmers' market, they would have picked them \\
out right there. And most of the time they pick them that day out of the garden. And they \\
taste better."
\end{tabular}


(range, 18-42 years), and most participants were not employed (employed, 34 percent; not

employed, 57 percent).

\section{ENC Participants}

In the ENC sample, half of the women currently shopped at a farmers' market or a produce stand. Most of the women did not have a garden, but some received produce from friends and family. Several themes surrounding the use of local food sources emerged from the ENC participants. From those women who currently shop at these sources, the following themes were identified as reasons for shopping there (number of participants who mentioned): freshness (8), perception of lower cost (3), taste of produce (3), prefer to buy locally (3), and ability to buy in bulk (3). Quotations to illustrate each of these themes are in Table 2.

ENC participants who did not currently procure food from local food sources gave the following reasons: do not know where it is located (9), inconvenient/not close to home or work (9), perception of higher cost (8), not in routine (6), lack of time (6), distrust of produce sold (4), lack of familiarity with the farmers' market experience (3), and do not accept SNAP/EBT (3). Quotations to illustrate each of these themes are in Table 3.

\section{WNC Participants}

In the WNC sample, most of the women shopped at farmers' markets or produce stands, had a garden or access to one, and received homegrown produce from friends and family. WNC participants who currently procured food from local food sources identified the following reasons for doing so: prefer to buy locally (5), freshness (4), convenient/close (4), to socialize (3), healthier/organic (3). Quotations to illustrate these themes are included in Table 4.

WNC participants who did not currently procure food from local food sources gave the following reasons: Inconvenient/not close to home or work (7), Have own garden (4), and Do not accept SNAP/EBT (3). Quotes to illustrate these themes are included in Table 5.

\section{Cross-cutting Themes}

A few main cross-cutting themes from both ENC and WNC participants developed from the interviews, including access to local food sources,

\section{Table 3. ENC Reasons for NOT Procuring Food from Local Food Sources}

\begin{tabular}{|c|c|}
\hline Theme & Quotation \\
\hline $\begin{array}{l}\text { Do not know where it is } \\
\text { located }\end{array}$ & $\begin{array}{l}\text { "I don't know where to find a farmers' market or anything. I see little stands on the side of the } \\
\text { road with like watermelons and strawberries and stuff and produce, but I don't even know } \\
\text { where a farmers' market is. No too much knowledge about this stuff. I haven't went looking } \\
\text { for it." }\end{array}$ \\
\hline $\begin{array}{l}\text { Inconvenient/not close to } \\
\text { home or work }\end{array}$ & $\begin{array}{l}\text { "If farmers' markets were closer in town, I think I would go there, but they're so far out, and } \\
\text { gas is so high...so that's what really, for me, would keep me from going to a farmers' } \\
\text { market." }\end{array}$ \\
\hline Perception of higher cost & $\begin{array}{l}\text { "Well sometimes I mean because it is locally grown, you would think it would be cheaper, but } \\
\text { sometimes it's not, just depending on which store has a sale on that week I guess." }\end{array}$ \\
\hline Not in routine & $\begin{array}{l}\text { "I guess it's, most of the time that I go once a month [to the supermarket], I try to get } \\
\text { everything that I need for the month, and 'cause I don't really like to grocery shop like that. I } \\
\text { just try to have everything that I need..." }\end{array}$ \\
\hline Lack of time & $\begin{array}{l}\text { "Yeah so like I guess if I had more time I would eventually visit the farmers' market, but right } \\
\text { now I gotta be in and out. That sounds really sad..." }\end{array}$ \\
\hline Distrust of produce sold & $\begin{array}{l}\text { "I don't know how they handle their food. I know who handles the food in [regional } \\
\text { supermarket]. I know they have their hands clean. I know you are supposed to wash your } \\
\text { food off before you cook it or eat it anyway, but still I know who handles it." }\end{array}$ \\
\hline $\begin{array}{l}\text { Lack of familiarity with the } \\
\text { farmers' market experience }\end{array}$ & $\begin{array}{l}\text { "Probably if somebody were you know take me out there, or you know introduce me to it than } \\
\text { I probably would go. Tell me how good the food is there, the vegetables and the produce." }\end{array}$ \\
\hline Do not accept SNAP/EBT & $\begin{array}{l}\text { "I don't think farmers' markets take food stamps. So that's why we will go to [regional } \\
\text { supermarket] instead of the farmers' market." }\end{array}$ \\
\hline
\end{tabular}


Table 4. WNC Reasons for Procuring Food from Local Food Sources

\begin{tabular}{ll}
\hline Theme & Quotation \\
\hline Prefer to buy locally & “It's local and I like to support local. And generally they use less pesticides than big \\
companies.” & “Just to get fresh organic stuff when it's in season, and to help support our farmers.” \\
\hline Freshness & “It's closer...And then I don't know of another one around. We like to go to get fresh stuff.” \\
\hline Convenient/Close & “Well, you know, socializing. I know pretty much everyone there. I see people I know. And they \\
To socialize & $\begin{array}{l}\text { know. It's more like a play date than a shopping trip. We may get something, and we may not } \\
\text { get something. We don't go there primarily to get food. I know I just said I do. I mean I do, I } \\
\text { do. I probably five times out of six I do get something, I leave with something." }\end{array}$ \\
\hline Healthier/Organic & $\begin{array}{l}\text { “ get our potatoes, beans, squash, apples, oranges. I'll get...Sometimes I'll get our meat } \\
\text { there because it's actually been slaughtered from animals that the farmers have raised } \\
\text { around here, so they don't have all the additives...like you get from [regional supermarket].” }\end{array}$ \\
\hline
\end{tabular}

\section{Table 5. WNC Reasons for NOT Procuring Food from Local Food Sources}

\begin{tabular}{ll}
\hline Theme & Quotation \\
\hline $\begin{array}{l}\text { Inconvenient/Not close to } \\
\text { home or work }\end{array}$ & "Part of it is convenience...It's easier for me to just go in the grocery store." \\
\hline Have own garden & $\begin{array}{l}\text { "Pretty much because my family grows - they have big gardens...so they usually just give me } \\
\text { bags of stuff." }\end{array}$ \\
\hline Do not accept SNAP/EBT & "I get food stamps, and they usually don't take them. And that's how we get our food." \\
\hline
\end{tabular}

acceptance of SNAP/EBT, freshness of produce, supporting local, and the social nature of shopping at local food sources. The following are quotations for each theme from each region:

Access (economic and geographic) to the farmers' market Women in both ENC and WNC reported that economic (financial) and geographic access to farmers' markets were influential in their decisions to procure food from local food sources.

ENC Participant: "Maybe if they could give out some vouchers for, which they've recently started doing, for farmers' markets and produce stands because this is the thing...When you look at our economy, can I take 20 [U.S.] dollars and go to the farmers' market and buy fresh fruits and vegetables or I can take 7 [U.S.] dollars and go to McDonald's and get everybody a supersized meal. So, if they make food that's healthier for us more accessible, and more economical, I really think people would do it."
WNC Participant: “Okay, um, it's kind of out of the way for me, and then my transportation, I'm having problems with my transportation right now. So, I try to do basic stuff, you know, in the area, close to home."

Acceptance of $S N A P / E B T$

Another cross-cutting theme was acceptance of SNAP/EBT at farmers' markets. Women reported preferring to use food sources such as supermarkets where their SNAP benefits were sure to be accepted.

ENC Participant: "The main reason that I don't [shop at farmers' markets] is because those, they don't accept food stamps, and that is how I pay for my groceries. And that is pretty much the reason...I wish that they took food stamps. You know it would be a lot of money for them, because there is a lot of people that get food stamps...I don't get a lot of stamps, so, I have to pinch, but I think if more places accepted food stamps, a lot of 
people would probably eat more healthier, as far as being able to go to the farmers' market."

WNC Participant: "As bad as it sounds, my food stamps are a big part of it. If I don't know for sure if they're gonna take them... It is embarrassing to get up there and be like...And they're like, 'We don't take EBT.' So a lot of those places like that, if I don't know for sure, I don't even try. 'Cause I don't wanna get caught up there and be like 'I'm sorry, you have to take all this back."

\section{Supporting Local}

Women in both regions shared that an important reason for procuring local foods was to eat locally and to support local farmers and the local economy.

ENC Participant: "I go to like support local farmers and businesses."

WNC Participant: "It's local [produce] and I like to support local."

\section{Freshness of Produce}

Both ENC and WNC women often mentioned the freshness of produce as a facilitator to shopping at farmers' markets and produce stands.

ENC Participant: "Because they always have the freshest stuff...Some days I go there, and they just picked the cabbage out of the field. You know, it's always fresh."

WNC Participant: "We like to go to get fresh stuff."

\section{The Social Nature of Local Food Sources}

Many participants discussed the social nature of local food sources as being an important part of the experience. Participants mentioned that they commonly went to shop at local food sources with their family members or friends, and that experiences with home-grown produce were often very social in nature. This was especially true among the WNC participants, where most either had a family garden or got home-grown produce from friends and relatives. Often this interaction was with a person from an older generation. The women also mentioned interacting with the producer as a positive aspect of the farmers' market shopping experience.

ENC Participant: "I do grow, during the summer; I grew cucumbers and tomatoes... Um, I just find it therapeutic, and it's something that my daughter and I can do together. She loves cucumbers, she could eat two or three a day...My grandparents had a garden."

ENC Participant: “It's fine, I know on Mother's Day we went to [the produce stand]. It's an outing. I like my child and my boyfriend's children to see where our food comes from, where it's grown, the work that goes into it..."

ENC Participant: "Yeah, um, I just kind of remember it bein' my best childhood memories, just being in the garden with my grandmother. And, um... you know that feeling of success, and I did it myself..."

One participant mentioned the difficulties of having children and completing shopping tasks:

ENC Participant: "If I didn't have any children then I would be more willing to take more time and go to get more produce, regardless of the distance, and be willing to do all of those things, and I'd be eating at more restaurants and that kind of stuff. It's just everything just changes when you have a baby, it's all about convenience and savings."

\section{Racial Differences in Procurement}

In general, findings in the ENC WRA were similar between blacks and whites. Blacks were more likely to mention quality, taste, and price as reasons for going to the farmers' market compared to Whites. Blacks were more likely to mention the product as expensive, not being in their routine, never having been to the farmers' market, and non-acceptance 
of SNAP/EBT as reasons for not going to farmers' markets compared to Whites. Whites more commonly cited lack of trust, shopping not being convenient, and not knowing the location of the farmers' market as reasons for not going to the farmers' market as compared to Blacks.

\section{Discussion}

Differences in the procurement of food from local food sources and the barriers and facilitators for doing so were found between the two distinct rural populations. ENC and WNC women were largely dissimilar in their reasons for procuring food from local food sources, with the only highly common reason being the freshness of produce. ENC women appeared to be more attracted to more tangible attributes (price, taste), and WNC women appeared to be more attracted to more intangible attributes (supporting local agriculture, socializing). This may reflect cultural differences in views of the utility of local foods between two distinct geographical regions, and may provide some evidence that views of local food sources are not necessarily homogenous across rural areas. Another factor that might explain these differences are racial and/or ethnic differences in views of local food sources, as the ENC sample had a larger Black population than the WNC sample, which mirrors the actual demographic difference between the two regions. We further examined this issue by splitting the results from the ENC sample by race. While finding some differences, there did not appear to be clear differences by race in citing tangible versus intangible reasons concerning farmers' market use. Therefore cultural differences between the ENC and WNC sample may better explain the differences in this study's findings. Leone et al. (2012) found some differences in reasons for shopping at farmers' markets by race and by rural/urban status. These potential cultural, racial, and geographic differences should be examined further in future studies. Thus, a "one size fits all" approach towards promoting local food sources across different rural areas and different demographic groups may not be the most effective approach. Interestingly, the reasons for not shopping at the farmers' market were largely similar between the two areas, including limited access/convenience and lack of acceptance of SNAP/EBT. These highlight typical problems of living in rural, lowincome areas, and strategies should focus on addressing these issues.

Our results were similar to what has been found in previous studies. Leone et al. (2012) found that major barriers to farmers' market shopping for local food procurement included not being able to use food-assistance program benefits and not knowing the location of a farmers' market, factors that were also identified by participants in this study. Racine et al. (2010) found that those with previous farmers' market experience were more likely to shop at farmers' markets than those without previous experience, and that lack of a local food source close to home and lack of transportation were important factors inhibiting shopping at farmers' markets. The findings from our study seem to support these findings, as multiple participants said they would feel more comfortable shopping at farmers' markets if they were more familiar with the experience of doing so. Participants across both ENC and WNC suggested that limited access, including both geographic and economic access, played a large role in their lack of use of local food sources.

Our findings further support the significance of the social aspects of local food procurement, showing that people are influenced to both shop and purchase from local food sources for social reasons. We found that people receive social support in the form of both receiving local food and learning to grow their own foods from both family and friends, and that this is a valuable aspect in their production and procurement of local foods. The human connection experienced in the arena of local foods is a unique aspect of local food procurement (Hinrichs, 2000). The literature seems to support the fact that procurement of local food is an activity of social significance. Previous research has found that sociability was a top reason for shopping at farmers' markets (Sommer, 1979), and that there is more social interaction per visit at a farmers' market compared to a visit to the supermarket (Sommer, Herrick, \& Sommer, 1981). These interactions include both vendor-to-patron and patron-to-patron interactions, both of which are important to the consumer. Research has found 
that among farmers' market managers, promoting social activity and a sense of community were frequently cited ways they felt the market was making community impact (Oberholtzer \& Grow, 2003), and that vendors also benefit from this social interaction with customers through social learning (Hinrichs, Gillespie, and Feenstra, 2004). Another group of case studies (Brown \& Miller, 2008; Gillespie, Hilchey, Hinrichs, \& Feenstra, 2007) suggested that because local foods are often more visible in public spaces compared to supermarkets, and because of the accompanying variety of social interactions that take place, farmers' markets are valued community institutions that promote civic engagement and social interaction. Further, by providing human connection at the convergence of food production and consumption, farmers' markets provide a source of "social embeddedness," where economics are embedded within social ties and social interaction (Hinrichs, 2000). This social connection, which includes the concepts of reciprocity and trust, is considered a hallmark of direct markets, making it unique compared to the typically less socially interactive supermarket shopping experience (Hinrichs, 2000).

Another prominent finding was the common social interaction that took place surrounding home-grown produce. While limited published research is available on this topic, some studies (Ban \& Coomes, 2004; Thomasson, 1994; WinklerPrins, 2002) have suggested that the social value of home-grown food is an important aspect of home food production for many growers, encouraging relationship- and community-building. A study in Toronto found that many gardeners saw sharing food from their gardens as a way to contribute to the lives of others, strengthen social ties, and develop a "common ground" with neighbors (Kortright \& Wakefield, 2011). Of the existing research that could be found in the literature on this topic, most of the studies examined urban environments outside the United States. One research study of older adults in rural North Carolina found that garden produce was the most common type of food sharing, with over 80 percent of the sample receiving home-grown produce (Quandt, Arcury, Bell, McDonald, \& Vitolins, 2001). They also found that older rural adults viewed food sharing, including garden produce, as an integral part of life in the community (Quandt et al., 2001). Our findings from a rural area of the United States are an important addition to an underresearched part of the literature. Further examination of the social nature of home-grown food in the United States is needed, particularly among rural populations.

Future strategies to encourage use of local food sources among low-income populations might consider improving access to local food sources in low-income areas, raising awareness of the locations of existing local food sources, familiarizing potential consumers with the local food source shopping experience, and increasing the amount of local food sources that offer SNAP/ EBT as payment for fruits and vegetables. Local food source outlets often use promotional messages that do not resonate with a low-income audience, and farmers' markets are often perceived as being exclusionary to this group (Govindasamy, Italia, \& Adelaja, 2002; Wolf, Spittler, \& Ahern, 2005). In turn, the purposive placement of local food venues to increase fruit and vegetable consumption among low-income groups may be undermined. For example, using messages that address issues that are applicable to lower-income audiences are more likely to be effective at promoting behavior change in these populations. The findings from this study might be used to inform and improve the local food source marketing messages aimed at lower-income individuals, particularly WRA. Based on our findings, messages might emphasize the potential price savings of local food sources, the freshness and taste of food sold at local food sources, the social experience of shopping at local food sources, and the safety of produce sold at local food sources.

This study has a few limitations. Participants were recruited using a convenience sample, and the thoughts expressed by those willing to participate may not be representative of WRA in other regions. The two samples (ENC and WNC) were slightly different on some demographic variables (race), which may explain some differences apart from the suggested geographic or regional differences. Our study was also limited to English speakers only, and did not include the important per- 
spectives of rural non-English speakers. The strengths of the study include the racially, geographically, and age diverse sample, the in-depth nature of data collection, and the strong qualitative methodological approach.

\section{Conclusions}

Our study further elucidates the barriers and facilitators to procuring fruits and vegetables from local food sources among rural low-income women of reproductive age. The findings from this study provide a deeper and more detailed understanding of the contextual factors surrounding local food procurement, a level of understanding that to our knowledge was previously missing from the literature. Future research should aim to build on the observed findings, particularly by exploring ways to overcome the mentioned barriers to local food procurement in light of existing policies and cultural norms, looking at differences in factors related to local food source procurement among various ethnic groups, and further examining the social nature of local food procurement. The findings from this study should help guide future policy and intervention efforts aimed at promoting fruit and vegetable consumption among rural, lowincome WRA.

\section{Acknowledgements}

Research reported in this publication was supported by Cooperative Agreement Number 5U48DP001944 from the Centers for Disease Control and Prevention and by the National Institutes of Health/National Cancer Institute under Award 5R03CA155362-02. Its contents are solely the responsibility of the authors and do not necessarily represent the views of the Centers for Disease Control and Prevention or National Institutes of Health.

\section{References}

Ban, N., \& Coomes, O. T. (2004). Home gardens in Amazonian Peru: Diversity and exchange of planting material. Geographical Review, 94(3), 348-367. http://dx.doi.org/10.1111/j.1931-0846.2004. $\underline{\text { tb00177.x }}$

Brown, C., \& Miller, S. (2008). The impacts of local markets: A review of research on farmers markets and community supported agriculture (CSA). American Journal of Agricultural Economics, 90(5), 1298-1302. http://dx.doi.org/10.1111/j.14678276.2008.01220.x

Byker, C., Shanks, J., Misyak, S., \& Serrano, E. (2012). Characterizing farmers' market shoppers: A literature review. Journal of Hunger and Environmental Nutrition, 7(1), 38-52. http://dx.doi.org/10.1080/19320248.2012.650074

Chiuve, S. E., Sampson, L., \& Willett, W. C. (2011). The association between a nutritional quality index and risk of chronic disease. American Journal of Preventive Medicine, 40(5), 505-513. http://dx.doi.org/10.1016/j.amepre.2010.11.022

Daly, L. E., Kirke, P. N., Molloy, A., Weir, D. G., \& Scott, J. M. (1995). Folate levels and neural tube defects: Implications for prevention. Journal of the American Medical Association, 274(21), 1698-1702. http://dx.doi.org/10.1001/jama.1995.03530210052 $\underline{030}$

Evans, A. E., Jennings, R., Smiley, A. W., Medina, J. L., Sharma, S. V., Rutledge, R., Stigler, M. H., \& Hoelscher, D. M. (2012). Introduction of farm stands in low-income communities increases fruit and vegetable among community residents. Health \& Place, 18(5), 1137-1143. http://dx.doi.org/ 10.1016/j.healthplace.2012.04.007

Fisher, A. (1999). Hot peppers and parking lot peaches: Evaluating farmers' markets in low income communities. Venice, California: Community Food Security Coalition. Retrieved from http://www.eatbettermovemore.org/SA/enact/ neighborhood/documents/community.farmers markets.tools.hotpepperspeaches.pdf

Fisher, B. D., \& Strogatz, D. S. (1999). Community measures of low-fat milk consumption: Comparing store shelves with households. American Journal of Public Health, 89(2), 235-237. http://dx.doi.org/10.2105/AJPH.89.2.235

Freeman, H. P. (1989). Cancer in the socioeconomically disadvantaged. CA: A Cancer Journal for Clinicians, 39(5), 266-288. http://dx.doi.org/10.3322/canjclin.39.5.266

GfK Custom Research North America. (2013). Today's primary shopper. New York: Private Label Manufacturers Association. Retrieved from the PLMA website: http://plma.com/2013PLMA GfK Study.pdf 
Gillespie, G., Hilchey, D. L., Hinrichs, C. C., \& Feenstra, G. (2007). Farmers' markets as keystones in rebuilding local and regional food systems. In $\mathrm{C}$. C. Hinrichs \& T.A. Lyson (Eds.), Remaking the North American food system: Strategies for sustainability (pp. 6583). Lincoln, Nebraska: University of Nebraska Press.

Govindasamy, R., Italia, J., \& Adelaja, A. (2002). Farmers' markets: Consumer trends, preferences, and characteristics. Journal of Extension, 40(1), 1RIB6. Retrieved from http://www.joe.org

Hinrichs, C. C. (2000). Embeddedness and local food systems: Notes on two types of direct agricultural market. Journal of Rural Studies, 16(3), 295-303. http://dx.doi.org/10.1016/S0743-0167(99)00063-7

Hinrichs, C. C., Gillespie, G. W., \& Feenstra, G. W. (2004). Social learning and innovation at retail farmers' markets. Rural Sociology, 69(1), 31-58. http://onlinelibrary.wiley.com/journal/10.1111/\% 28ISSN \%291549-0831

Jilcott Pitts, S. B., Wu, Q., McGuirt, J. T., Crawford, T. W., Keyserling, T. C., \& Ammerman, A. S. (2013). Associations between access to farmers' markets and supermarkets, shopping patterns, fruit and vegetable consumption and health indicators among women of reproductive age in eastern North Carolina, USA. Public Health Nutrition, 16(11), 1944-1952. http://dx.doi.org/10.1017/S1368980013001389

Kortright, R., \& Wakefield, S. (2011). Edible backyards: A qualitative study of household food growing and its contributions to food security. Agriculture and Human V alues, 28(1), 39-53. http://dx.doi.org/10.1007/s10460-009-9254-1

Larson, N. I., Story, M. T., \& Nelson, M. C. (2009). Neighborhood environments: Disparities in access to healthy foods in the U.S. American Journal of Preventive Medicine, 36(1), 74-81. http://dx.doi.org/10.1016/j.amepre.2008.09.025 Leone, L. A., Beth, D., Ickes, S. B., MacGuire, K., Nelson, E., Andrew Smith, R., Tate, D. F., \& Ammerman, A. S. (2012). Attitudes toward fruit and vegetable consumption and farmers' market usage among low-income North Carolinians. Journal of Hunger \& Environmental Nutrition, 7(1), 64-76. http://dx.doi.org/10.1080/19320248.2012.651386
Liese, A. D., Weis, K. E., Pluto, D., Smith, E., \& Lawson, A. (2007). Food store types, availability, and cost of foods in a rural environment. Journal of the American Dietetic Association, 107(11), 1916-1923. http://dx.doi.org/10.1016/j.jada.2007.08.012

Lin, B.H. (2005, September 1). Diet quality usually varies by income status. Amber

Waves (newsletter from the U.S. Department of Agriculture, Economic Research Service).

Lutfiyya, M. N., Chang, L. F., \& Lipsky, M. S. (2012). A cross-sectional study of US rural adults' consumption of fruits and vegetables: Do they consume at least five servings daily? BMC Public Health, 12, 280. http://dx.doi.org/10.1186/14712458-12-280

McCormack, L. A., Laska, M. N., Larson, N. I., \& Story, M. (2010). Review of the nutritional implications of farmers' markets and community gardens: A call for evaluation and research efforts. Journal of American Dietetic Association, 110(3), 399-408. http://dx.doi.org/10.1016/j.jada.2009.11.023

Morton, L. W., \& Blanchard, T. C. (2007). Starved for access: Life in rural America's food deserts. Rural Realities, 1(4), 1-9. http://www.ruralsociology.org

Oberholtzer, L., \& Grow, S. (2003). Producer-only farmers' markets in the mid-Atlantic region: A survey of market managers. Arlington, Virginia: Henry A. Wallace Center for Agricultural and Environmental Policy at Winrock International.

Powell, L. M., Slater, S., Mirtcheva, D., Bao, Y., \& Chaloupka, F. J. (2007). Food store availability and neighborhood characteristics in the United States. Preventive Medicine, 44(3), 189-195. http://dx.doi.org/10.1016/j.ypmed.2006.08.008

Quandt, S. A., Arcury, T. A., Bell, R. A., McDonald, J., \& Vitolins, M. Z. (2001). The social and nutritional meaning of food sharing among older rural adults. Journal of Aging Studies, 15(2), 145-162. http://dx.doi.org/10.1016/S0890-4065(00)00023-2

Racine, E. F., Smith Vaughn, A., \& Laditka, S. B. (2010). Farmers' market use among African-American women participating in the Special Supplemental Nutrition Program for Women, Infants, and Children. Journal of the American Dietetic Association, 110(3), 441-446. http://dx.doi.org/10.1016/j.jada.2009.11.019 
Ray, J. G., Wyatt, P. R., Vermeulen, M. J., Meier, C., \& Cole, D. E. C. (2005). Greater maternal weight and the ongoing risk of neural tube defects after folic acid flour fortification. Obstetrics and Gynecology, 105(2), 261-265. http://dx.doi.org/10.1097/ 01.AOG.0000151988.84346.3e

Sharkey, J. R., \& Horel, S. (2008). Neighborhood socioeconomic deprivation and minority composition are associated with better potential spatial access to the ground-truthed food environment in a large rural area. Journal of Nutrition, 138(3), 620-627. http://in.nutrition.org/

Sinning, A. R. (1998). Role of vitamin A in the formation of congenital heart defects. Anatomical Record, 253(5), 147-153. http://dx.doi.org/ 10.1002/(SICI) 1097-0185(199810)253:5\% 3C147::AID-AR8\%3E3.0.CO;2-0

Sommer, R. (1979). Farmers' markets-Myths and realities. California Agriculture, 33(2), 12-14. http://dx.doi.org/10.3733/ca.v033n02p12

Sommer, R., Herrick, J., \& Sommer, T. R. (1981). Behavioral ecology of supermarkets and farmers' markets. Journal of Environmental Psychology, 1(1), 1319. http://dx.doi.org/10.1016/S02724944(81)80014-X

Thomasson, D. (1994). Montserrat kitchen gardens: Social functions and development potential.
Caribbean Geography, 5(1), 20-31.

U.S. Census Bureau. (2013, June). State \& County Quickfacts: Madison County, N.C. Retrieved December 4, 2013, from http://quickfacts.census.gov

Winkleby, M. A., Jatulis, D. E., Frank, E., \& Fortmann, S. P. (1992). Socioeconomic status and health: How education, income, and occupation contribute to risk factors for cardiovascular disease. American Journal of Public Health, 82(6), 816-820. http://dx.doi.org/10.2105/AJPH.82.6.816

WinklerPrins, A. M. G. A. (2002). House-lot gardens in Santarém, Pará, Brazil: Linking rural with urban. Urban Ecosystems 6, 43-65. http://dx.doi.org/10.1023/A:1025914629492

Wolf, M. M., Spittler, A., \& Ahern, J. (2005). A profile of farmers' market consumers and the perceived advantages of produce sold at farmers' markets. Journal of Food Distribution Research, 36(1), 192-201. http://purl.umn.edu/26768

World Health Organization [WHO] \& Food and Agriculture Organization of the United Nations [FAO]. (2004). Vitamin and mineral requirements in human nutrition ( $2^{\text {nd }}$ ed.). Geneva: World Health Organization. Retrieved from http://www.who.int/nutrition/publications/micro nutrients/9241546123/en/ 